RECONSIDERING SCHUMPETERIAN OPPORTUNITIES: THE

CONTRIBUTION OF INTERACTION RITUAL CHAIN THEORY

Published in

INTERNATIONAL JOURNAL OF ENTREPRENERIAL RESEARCH AND

BEHAVIOUR, 13;1. 2007

Professor David Goss

Surrey Business School

University of Surrey

Guildford,

GU2 7XH

d.goss@surrey.ac.uk 


\title{
RECONSIDERING SCHUMPETERIAN OPPORTUNITIES: THE CONTRIBUTION OF INTERACTION RITUAL CHAIN THEORY
}

\begin{abstract}
This paper develops a novel interactionist theory of entrepreneurial conduct to explore the nature of Schumpeterian opportunities. Specifically, it draws attention to the significance of social interaction and emotion for the enactment of effective business innovation. Deploying constructs drawn from Randall Collins's 'interaction ritual chain theory', the paper provides a model of the entrepreneurial process that specifies the social conditions necessary for innovative ideas to be translated into effective business activity. Examples drawn from the development of the personal computer industry are used to illustrate this argument. It is concluded that 'interaction rituals' can contribute to an understanding of individuals' and groups' ability to overcome the barriers of social inertia, scepticism and hostility that frequently confront attempts to establish genuine commercial innovations.
\end{abstract}

\section{Introduction}

A central distinction in entrepreneurial theory is that between Schumpeterian and Kirznerian opportunities (Schumpeter, 1934; Kirzner, 1973). According to Shane (2003, p. 21), Schumpeterian opportunities are disequilibrating, depend upon new information, are highly innovative, rare, and involve processes of creation - the entrepreneur has to work, often in the face of opposition from vested interests or social inertia, to establish new ways of doing things and turning these into a viable business. Kirznerian opportunities, in contrast, are depicted as equilibrating, having limited, or no, reliance on new information, being less innovative, more common, and relying on discovery rather than creation (e.g., finding more effective ways of exploiting an existing business idea). In summary, Schumpeterian opportunities 'break away from existing knowledge', while Kirznerian opportunities 'replicate existing organizational forms’ (Shane 2003, p. 21).

The ability to spot and exploit Schumpeterian opportunities is held to be of considerable significance because of the latter's profound impact on economic and 
social development, prompting attempts to explain why some individuals rather than others have this apparent ability. Cognitive process theories have predominated in this field (e.g., Markman and Baron, 2003; Baron, 1998; 2004; Mitchell et al, 2002; 2004), but network/structural analysis have also made significant contributions (YliRenko et al, 2001; Greve and Salaff, 2003; Neergaard et al, 2005; Burt, 2000). Cognitive perspective have prioritised individual mental processes involved in opportunity spotting (Shane, 2003) whereas network approaches have focused either on the positional structure of networks, or 'embeddedness', that is, the socio-cultural assumptions that underpin market relations (Granovetter, 1985; Jack and Anderson, 2002). Valuable as such perspectives are, neither has given detailed consideration to the full range of entrepreneurship’s experiential dimensions, most notably its emotional component.

Although there is a large and plausible body of non-academic material that suggests a prima facie case for regarding entrepreneurialism as a deeply emotional activity (e.g., Bower, 1988; 1993; Roddick, 2000; Branson, 2000; see also Kets de Vries, 1996; Goss, 2005a; 2005b), entrepreneurship has not yet followed other areas of social science in making emotion a key explanatory variable (Ashkanasy et al, 2002; Fineman, 2003; Gabriel and Griffiths, 2002; Lupton, 1998). As this 'emotive’ dimension of behaviour is captured in many aspects of Schumpeter's own characterisation of the innovative entrepreneur (1934: 86ff) - not to mention Keynes's notion of 'animal spirits' (see Zafirovski, 1999) - it is all the more surprising that it attracted so little theoretical attention. This paper draws upon Collins’s (2004; 1990) ‘interaction ritual chain theory’ to suggest a novel conception of innovative entrepreneurial behaviour. Collins's work has been chosen for this task because his 
concepts of emotional energy and interaction ritual chains provide opportunities to complement and extend existing work based on cognitive process and network theories of entrepreneurship. We begin by outlining the key components of this theory before proposing our model of Schumpeterian entrepreneurship.

\section{Interaction Ritual Chain Theory.}

The essence of Collins's Interaction Ritual Chain theory (IRC) is that individuals are attracted towards some types of situation and away from others on the basis of what he terms ‘emotional energy’ (EE): ‘EE gives energy, not just for physical activity . . . but above all for taking the initiative in social interaction, putting enthusiasm into it, taking the lead in setting the level of emotional entrainment.' (2004, p. 107; emphasis added). This is a concept that refers to a long-term 'emotional tone' rather than to one specific emotion. Emotional energy is regarded as a 'distinctively human blend of emotion and cognition'. The former is experienced, according to Collins, on a scale of feelings from an 'up' tone of excitement and happiness to a 'down' tone of depression and sadness. The cognitive component of EE operates through our memory's ability to attach an emotional charge to significant symbols, resulting in 'an expectation of being able to dominate particular kinds of situations, or to enact membership in particular groups’ (2004, p. 116). ${ }^{1}$

Emotional energy itself is generated through participation in interaction rituals. These are composed of four 'ingredients’: (i) group assembly; (ii) barriers to outsiders; (iii) a mutual focus of attention; and (iv) a shared mood. If the interaction is successful the result is an immediate sense of 'collective effervescence' and longer term ritual outcomes in the form of: (a) group solidarity; (b) emotional energy in the individual; (c) symbols of social relationships (equivalent to sacred objects); and (d) shared 
standards of morality (see 2004, p. 45ff for detailed accounts of these elements). Symbols are particularly important as, when committed to memory, they enable individuals cognitively to 'store' (and restore) the emotional energy generated during the ritual, prolonging its intensity even when no longer actively participating, sensitising and directing attention towards attractive or unattractive opportunities for future interaction (2004, p. 81ff).

Chains of interaction rituals constitute individual biographies and collective social life - 'society' is envisaged as interconnecting networks of interaction ritual chains. For the individual, participation in successful rituals generates high levels of EE and a desire to repeat them; unsuccessful rituals generate little EE (or even lose it) and are avoided. Through participation in such rituals - which constitute most forms of collective social activity, from family groups to formal organizations - individuals develop interaction orientations that pull and push them from situation to situation: 'The relative degree of emotional intensity that each IR reaches is implicitly compared with other IRs within those persons' social horizons, drawing individuals to social situations where they feel more emotionally involved, and away from other interactions that have a lower emotional magnetism or an emotional repulsion.' (Collins, 2004, p. xiv).

However, as IRC theory's analytical starting point is micro-level interactions within social situations, this immediately lays it open to two lines of criticism. The first is that its micro-focus neglects social structure and, therefore, fails adequately to locate patterns of interaction within a wider social context. Although the immediate focus may be on the details of the situation (not least because this is so often missing from 
contemporary social theory), interaction ritual chain theory, as its name suggests, is also concerned to connect ritual situations in a manner compatible with network analysis. As we discuss in our concluding section, this provides opportunities to link with macro-structural approaches (Collins, 2004, p. 259; 1981; Barnes, 2000). The second criticism is that IRC theory's concern with the causal effect of situational factors denies any role for human individuality, that is, it lacks a sense of agency. It would be more correct, however, to say that IRC theory lacks a notion of unconditional agency. IRC theory can link to individual cognitive processes and, in this regard, leaves room to account for all manner of individual and idiosyncratic thoughts and actions - whilst still insisting that the pathway to these experiences remains deeply social (Collins, 2004, p. 345ff; see also Baehr, 2005 and Smardon, 2005).

It should be possible, therefore, using IRC theory, to specify the sorts of interaction rituals that will produce particular types of action and the social conditions within which this is most likely to be successfully performed (Goss, 2005a). We will, therefore, attempt such a specification in relation to Schumpeterian entrepreneurship. Figure 1. offers a provisional model of the process of opportunity development and enactment, framed in terms of interaction rituals. We begin by discussing it in broad terms before elaborating through a case study of the emergence of the personal computer industry. 


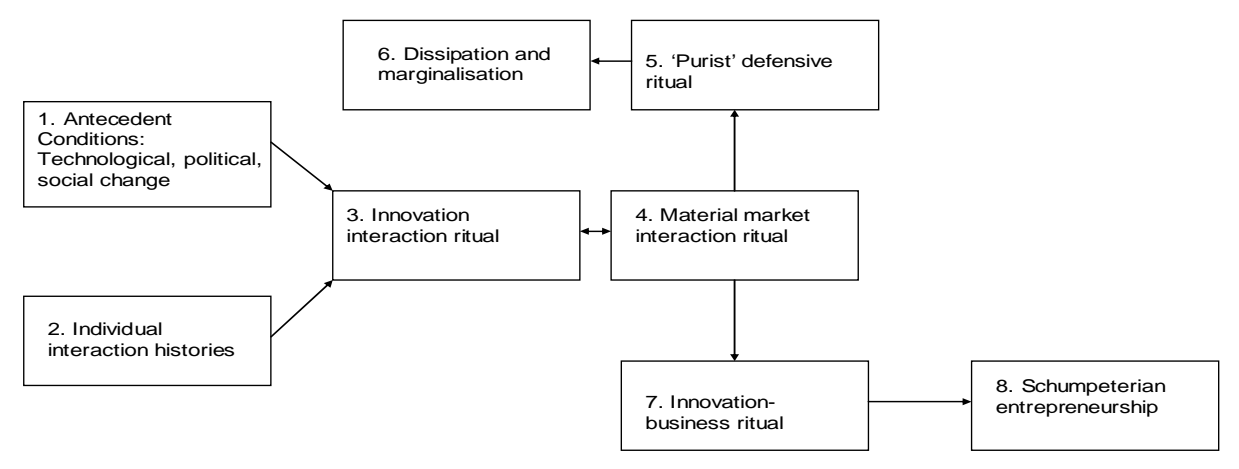

Figure 1 indicates the processes through which individuals, interacting with others in patterned ways, can generate the motivating emotional energy to progress innovative entrepreneurial ideas. Antecedent conditions (box 1) provide the raw materials of innovation, but often their significance as an entrepreneurial opportunity is either not widely recognised or not considered a practical possibility for development (Shane, 2003; Schwartz et al, 2005). We conjecture that around any change process there will be particular individuals or groups whose previous social relationships have created a strong emotional commitment to a particular type of emerging new idea, usually through involvement with a related or analogous activity (box 2). When applied to a new innovation, this ‘emotional energy' can become an attractive force for others with a similar interest in the innovation, creating the basis for forms of group assembly that focus attention on this new project. This shared interest and involvement creates an interaction ritual around the innovation which, if successful, generates ‘collective effervescence’ and a sense of solidarity, the effects of which 
reinforce and further enthuse participants commitment to the project and drawing the attention of wider audiences (box 3). Only if such innovation- or enthusiast-rituals are successful is there likely to be a basis for commercial development - either because the ritual draws in large numbers of converts, thereby creating a market for ritual materials in its own right, or because it attracts participants who have the connections and/or resources to promote their 'enthusiasm' as a business opportunity. At this stage the 'innovation ritual' has to mesh with the 'material market rituals' of the commercial world (box 4). This process of fusion is inevitably problematic. On the one hand, enthusiasts who have no emotional attraction to business rituals may regard commercialisation as a 'sell-out' or a betrayal of the original innovative ideal, focusing their efforts on alternative 'pure' forms of development (box 5). However, unless this alternative attracts large numbers of adherents prepared to support the 'pure' ritual from their own resources, it is likely to dissipate emotional energy and become increasingly marginalised, if not forgotten (box 6). Alternatively, where enthusiasts gain emotional energy and collective solidarity from combining innovation and market rituals (box 7), there is the potential for self-sustaining development, and it is this 'hybrid' ritual configuration that creates the conditions for Schumpeterian entrepreneurship: individual emotional energy drives innovation, group solidarity enables the development of viable commercial organization, each reinforcing the other. We can now illustrate this process by examining the development of the personal computer industry.

Interaction ritual, entrepreneurship and the personal computer: a conjectural case study.

The personal computer (PC) industry has been chosen to illustrate the contribution of emotionally fuelled social interaction to entrepreneurial behaviour for the following 
reasons. Firstly, the PC sector is economically significant and is generally recognised as an instance of the realisation of a Schumpeterian opportunity, as defined above (Campbell-Kelly, 1995; Langlois, 1994; Steinmueller, 1995). Secondly, its initial and most creative stage of development was temporally and geographically contained (limiting the intervening effect of contingent factors) and, as a relatively recent phenomenon, we are better placed to appreciate the context of social meaning that surrounds its development than with more historically distant cases. Finally, it is reasonably well documented, both by analysts and participants. The following sections offer a reading of this industry's development through the lens of interaction ritual chain theory.

The following account suggests how a largely technology-focussed interaction ritual contributed to the sector's early developments, but was expanded and 'meshed' with business/market rituals to create a highly motivating entrepreneurial environment for those energised by both modes of interaction. The so-called 'triumph of the nerds' (Cringely, 1996; 2005a/b/c) is generally hailed as the epitome of technological entrepreneurship: visionary individuals combining technical expertise with business acumen to force a new industry into being - in the face of widespread scepticism. The account offered below does not deny the effect of individual powers, but rather seeks to show that their realisation needs to be understood within a wider context of social interaction, the emotional dynamics of which may be significant in overcoming barriers - in particular inertia and scepticism - that are likely to confront a genuinely innovatory practice. First we seek to demonstrate that, despite its technological innovation, the PC's initial appeal, and the basis of its marketability, can be understood as part of an already developing collective social activity that we identify 
as a form of interaction ritual focussed on computing. However, because of the relatively small number of accessible (mainframe and mini-) computers, this remained, for most, an incomplete ritual. The market for personal computers, we suggest, can be interpreted as having developed initially out of a desire amongst a growing group of electronics enthusiasts for ritual fulfilment, rather than an as a new commercial opportunity spotted by an astute entrepreneur. Our second claim is that this new form of computer ritual, with its associated demand for the PC as a membership symbol, created a sense of 'collective effervescence' that laid the basis for innovative entrepreneurial development. This was driven by those who, by dint of their individual interaction histories, were able to operate across the rituals of computing and business, producing a sense of pioneering solidarity amongst collaborators and strongly motivating emotional energy in individuals. Such a combination, we contend, encouraged energetic and committed perseverance in the face of widespread scepticism from 'informed opinion' of the time, which branded personal computing a niche fad, of relevance only to 'techno-nerds'. In entrepreneurial terms, our argument suggests that the effective meshing of computing and business rituals proved a potent force as the sector developed.

The section develops broadly in line with Figure 1 above ('broadly', because, in practice, the boundaries of the model's components are to be regarded as overlapping and interpenetrating rather than part of a strictly linear 'flow'). Sub-section (a) begins by examining the antecedent conditions, the emergence of an innovation interaction ritual based on computing and their consequences for individual biographies and action-orientations (boxes 1, 2 and 3). This is followed by (b) a consideration of the meshing of innovation and market rituals (boxes 2, 3 and 4). The final sub-section (c) 
discusses the divergent paths of ritual dissipation (boxes 5-6) and ritual expansion towards the creation and realisation of a Schumpeterian opportunity (boxed 7-8).

a) Antecedents, individual interaction histories and emergent innovation rituals.

The arrival of the personal or micro-computer in the mid-1970s represented a revolutionary development of the existing computer industry, creating a sector that, at least initially, shared little of the latter's hardware, software or business structures (Campbell-Kelly, 1995; Langlois, 1994; Steinmueller, 1995). Although quite distinct from the then dominant mainframe and mini-computers, the PC's development cannot be divorced from this heritage, the social dimensions of which are readily viewed through the lens of interaction ritual and emotional dynamics. Computing at this time was regarded as high science, with relatively few participants, but a high public profile. Science fiction writing, in particular, presented computing as an exciting combination of romance and danger, frequently emphasising its ritual, almost quasireligious, qualities: the machine as 'sacred object', protected by white-coated 'guardians' and accessible only through an esoteric language.

But until the PC's birth, direct and full participation in the real rituals of computing was rare; computers were few and located within military, educational and corporate premises with strictly controlled access (Naughton, 2000). Although full participation in computer ritual remained limited, its symbolic language - code - was more widely accessible and came to exercise a strong grip on the imaginations of many 'young male technophiles’ (Cambell-Kelly, 1995, p. 92; Collins, 2004, p. 352). Programming languages offered partial participation in computer ritual and, for those with a mathematical inclination, appeared (than as now) to be a potent source of emotional 
energy $^{2}$ (see further below). Programming also became a reason for group assembly, driven by a desire to share knowledge and, more pragmatically, because the limited availability of computers usually necessitated sharing time and costs. Programming languages, we would suggest, created a natural focus of attention, a symbol of membership and barrier to outside participation. This constituted the basis for a form of computer IR that could be widely shared amongst enthusiasts; but it remained a ritual built around a missing ingredient - the computer itself.

Nevertheless, by the early 1970s, programming ritual appears to have created a pentup demand for computer access. In 1975, however, the producer of the Altair 8800, the first PC to become available for purchase, seemed almost totally unaware of its commercial potential ${ }^{3}$. Being interviewed by the computer journalist Robert Cringely (2005a, p. 6), the inventor of this machine, Ed Roberts (a struggling manufacturer of electronic calculators), recounts its development as driven by personal desire to participate in hands-on computing, rather than to initiate a 'killer business opportunity': 'There were some of us that lusted after computers really at that time. All the computers in the world tended to be in big centres and you had to get permission to get close to them, and you know, nobody had access to computers. And the idea that you could have your own computer and do whatever you wanted to do with it, whenever you wanted to, was fantastic.' Roberts anticipated that he would sell no more than a few hundred a year - within a month he was getting two hundred and fifty orders a day.

The Altair was 'advertised to hobbyists in the popular technical press and sold by mail order for construction from parts ... The computer was programmed by hand 
switches and did not do anything remotely useful.’ (Cambell-Kelly, 1995, p. 92;

Frieberger and Swaine, 1984). We conjecture that the first PC was an object produced by a hobbyist (albeit with access to manufacturing capability) for use in 'hobby' rituals; it was less a profit-opportunity spotted, than a ritual extended. From an IRC theory perspective, the Altair's success was not merely the result of entrepreneurial judgement (either in terms of opportunity spotting or subsequent marketing) but appears to have been driven, in large part, by enthusiasts' attraction to the EE potential of participating in 'real' computing ritual.

\section{b) Meshing material market rituals and innovation rituals}

The ways in which Altair owners used their machines supports this interpretation. Its very lack of obvious functionality often made it a focus for group assembly: the clubs formed to play with and talk about this new 'toy', generating excited conversation and high levels of involvement. Accounts of the Homebrew Computer Club of Stanford capture how the need to 'programme' the computer by repeatedly flipping switches would be watched avidly by members, creating a form of 'rhythmic entrainment' often for extended periods - and a shared mood of excitement when the machine successfully executed basic instructions (see Cringely, 2005a, p. 8; Letiche and Hagemeijer, 2004)

These group assemblies expanded with the boom in user-conventions and computer fairs in the late 1970s, providing opportunities for large-scale collective assembly, within which local rituals could be developed around particular types of hardware or software activity, creating powerful pockets of ritual intensity where participants 
'pumped up' and circulated symbols through technical conversation and hands-on engagement with their technology.

Many of the earliest PC companies emerged out of just such intense ritual gatherings, but it is doubtful whether this conversion from 'computer interaction ritual' to 'business/market ritual' can be described adequately in terms of conventional entrepreneurial decision-making, i.e., spotting and exploiting an opportunity for profit. It could be argued that Microsoft founders Bill Gates and Paul Allen’s decision to produce a version of BASIC for the Altair was a genuinely opportunity-spotting move in classic entrepreneurial style. Certainly the retelling of this 'road to Damascus' incident has all the qualities of an innovatory idea focused on a potential business opportunity unseen by others. It is usually recounted how Allen and Gates saw the Altair featured in Popular Electronics magazine (Cringely, 1996, p. 53); as Gates recalls: 'Paul [Allen] kept saying, “Let’s start a company. Let’s do it.” We realized that the revolution might happen without us. After we saw that article, there was no question of where our life would focus.' (Lowe, 1998, p. 22). After successfully producing a version of BASIC for the Altair, they moved to Albuquerque (Gates abandoning his Harvard degree) to be near MITS (the Altair manufacturer) and established Microsoft as a business selling software, first to MITS and then to the other manufacturers who produced similar machines.

Such an account of apparent visionary genius, however, is not incompatible with an IRC theory explanation. First, Gates and Allen had, from their early school days, been thoroughly enmeshed in computer-focussed interaction ritual chains which provided a rich source of EE for both. The idea to write BASIC for the Altair cannot be seen as a 
purely cerebral inspiration; rather, from an IR perspective, it was an 'opportunity' because of its ritual and EE potential, an incitement to extend an existing and valued, albeit underdeveloped, ritual activity. Members of the conventional computer industry found the Altair's attraction incomprehensible for precisely the same reason that enthusiasts outside the industry were captivated by it: the former's rituals were firmly tied to the mainframe and minicomputers over which they had exclusive control, but for the latter, this very exclusion made the Altair a key to ritual completion (see Naughton, 2000, p. 94). Gates and Allen’s anticipated 'revolution’ seems to have been as much about the forging of a new form of computer ritual as about a purely commercial opportunity.

But the commercialism of even the early Microsoft cannot be denied. It seems clear that from an early age (before their programming obsession), both Gates and Allen were emotionally energised by competitive situations, especially (in Gates’ case) those involving money (Lowe, 1998, p. 1ff); as he was later to remark: 'Business is a good game. Lots of competition and a minimum of rules. You keep score with money.' (Gates, cited in Lowe, 1998, p. 156). The activity of programming created a similar emotional 'high' (as well as collective effervescence and group solidarity): We didn’t even obey a 24 hour clock, we'd come in and programme for a couple of days straight. We'd - you know, four or five of us, when it was time to eat we'd all get in our cars, kind of race over to the restaurant and sit and talk about what we were doing, sometimes I'd get excited talking about things, I'd forget to eat, but then you know, we'd just go back and programme some more. It was us and our friends - those were fun days. (Cringely, 2005a, p. 3) Microsoft, we suggest, was a vehicle to fuse these two powerfully motivating sources of emotional energy: competitive market ritual and computer ritual; the ability to 
maintain a central position in both created the basis for their entrepreneurial success. In IRC theory terms, such an orientation towards these types of IR is the ongoing product of a chain of previous interactions such that 'opportunities' are sought and constructed within EE-generating networks rather than 'spotted' on the basis of 'superior cognitive capabilities’ alone. ${ }^{4}$

\section{c) Ritual dissipation and ritual expansion.}

By the late 1970s the meshing of computer ritual and material market ritual appeared well underway, reflected in significant financial gains for many of the early enthusiasts. Such early business success can be interpreted as an almost incidental consequence of computer ritual's take-off, and in numerous cases the latter remained the dominant interest: business revenues provided a convenient way to finance greater technical innovation - hence Cringley’s (1996) notion of ‘accidental empires’. However, once a material market for ritual objects becomes established, IRC theory suggests that the originating ritual will have to incorporate, or be made compatible with, the ritual interactions and symbols of that material market, such as corporate governance standards, employment contracts, financial and accounting conventions, logistics, etc. This point of intersection makes ‘entrepreneurial opportunities’ possible, but it is also a site of ritual tension and potential conflict. For instance, whereas the original PC ritual was almost exclusively confined to enthusiasts, the emerging material market widened participation to those who lacked the symbolic capital of computing, but who were equipped to operate within the rituals of business (finance, marketing) and who had access to its symbolic (and literal) capital, money. However, when a material market emerges successfully 'on the back' of an interaction ritual, the former seems likely to become increasingly indispensable to that 
ritual's maintenance and, especially, its expansion and intensification. In the PC industry of the early 1980s this was exemplified by struggle between $\mathrm{CP} / \mathrm{M}$ and (Microsoft) DOS for operating system dominance.

Gary Kildall, founder of Intergalactic Digital Research, had invented the CP/M operating system that was the basis of virtually all PCs until the late 1970s. Kildall's obsession was technology (he is quoted as likening programming to a religious experience; Cringely, 1996, p. 61) and whilst the ubiquity of his product had made him rich, he had little interest in business development (patenting products, professional management, etc.). Bill Gates, in contrast, whilst retaining a central position within computer IR through his programming activity and convention attendances, was also driven to exploit the commercial potential of his products (see above). Business rituals and symbols were incorporated early into the 'backstage' operations of the Microsoft organization, motivated, by the explicitly stated goal of winning the market 'game' (see Cringley, 1996 and above).

There is now a widespread acceptance that the key factor in DOS's supplanting of $\mathrm{CP} / \mathrm{M}$ as the industry standard was Microsoft's deal to supply DOS for IBM's first PC. The latter was a 'late starter' in the PC market having regarded it, along with most of the mainframe computer industry, as a niche product of no real commercial potential. We hypothesise that the differing EE-generating configurations of Intergalactic and Microsoft contributed to the latter's 'interaction advantage' in concluding the operating system deal, a move that led to the commercial dominance of what many experts then regarded as a technically less sophisticated product (Gandal et al, 1999; Campbell-Kelly, 1995). 
In 1980, apparently under the impression that Gates could supply them with both an operating-system and a programming language, IBM approached Microsoft to help develop their own PC - a prospect that hugely excited Gates as it offered the opportunity to break into a global business market. However, Microsoft’s Soft Card used CPM under licence from Kildall’s company. According to Cringely’s (1996) account, pieced together from participants, Gates, anxious to secure the deal for his software, arranged for the IBM representatives to meet Kildall with a view to securing a jointly owned product. Kildall, however, unlike Gates, seemed unwilling and uninterested in engaging in IBM's rituals of corporate power. Gates and his Microsoft managers appear to have shown due deference and enthusiasm for the rituals of corporate business dealing - signing non-disclosure agreements, treating IBM as a valued client, even putting on suits and ties! Kildall, in contrast, seems deliberately to have displayed disdain and indifference towards these conventions, cancelling a prearranged meeting to indulge his new flying hobby, keeping the IBM delegates waiting all day and, finally, entering into a hostile dispute over the non-disclosure agreement. The result was the IBM team's refusal to deal with Kildall. Gates, in contrast, was desperate to deal with IBM and secured his own operating system (a version produced by the small SCP company and, apparently, a virtually straight copy of Kildall’s unpatented system). According to one of his associates: 'We just got carried away and said, 'Look, we can’t afford to lose the language business. That was the initial thought - we can't afford to have IBM not go forward. This is the most exciting thing that's going to happen in PCs.' (Cringely, 2005b: 8; emphasis added). For Kildall, business deals seem to have been an EE-drain (something to be avoided), whereas for Gates and associates they were an EE-boost, symbolically fused with computer ritual. Gates 
bought out SCP for \$50k outright and, through the deal with IBM, retained the right to licence it to any other manufacturer for up to $\$ 50$ per PC (a contractual coup that many attribute to the failure of the IBM team, still wedded to a business ritual informed by mainframe and mini-computing, to fully appreciate the potential for growth in the PC market). The result was Microsoft's inexorable rise and Gary Kildall’s commercial demise.

In summary, our model suggests that the initial emergence of a material market focused on the PC can be seen as a direct consequence of the diffusion of a new form of computer ritual, knowledge of which spread through popular culture and specialist magazines, meetings and conversations. Although a commercial opportunity, the first PC was also, and possibly primarily, an attempt to intensify this emerging ritual by providing an accessible 'sacred object'. Its success in this regard created and fuelled a material market for ritual objects and symbols. This fusion of computer ritual and material market ritual provided situations that could generate the intensity of EE and group solidarity necessary to create commercially viable entrepreneurial ventures, despite the widely held view in the 'mainstream' computer industry of the day, that the PC was little more than a niche product of limited long-term significance.

\section{Concluding Discussion.}

Theoretically, the model developed here points towards potentially interesting connections with more structurally focused approaches to entrepreneurship through the notions of 'embeddedness' and social networks. Embeddedness has been widely used as a means of conceiving the relationship between economic or material markets and wider patterns of social and cultural relations (Granovetter, 1985; DiMaggio, 
2002, Jack and Anderson, 2002; Collins, 2004). Specifically, markets are considered to be embedded within socio-cultural networks that create the social conditions necessary for the former's operation, via the determination of ground rules that specify how exchange should be carried out, and the establishment of shared trust amongst participants. Within our model, the notion of 'ground rules' links naturally to the discursive/symbolic aspects of interaction ritual, shared trust can be seen as analogous to social solidarity (membership status), and the extent to which the same individuals participate together in recurrent rituals could give measures of network stability/density. Interaction ritual theory, however, by emphasising the role of emotion, helps to explain not only the 'positional' quality of networks but also their internal dynamics - how, through the matching up of membership symbols and emotional energies, network ties are created or severed, entered into with enthusiasm or reluctance, and individuals welcomed or excluded (Collins, 2004, p. 166; Smith, 2004; Douglas, 2005). Conceived in this way, interaction rituals qua networks can be seen as the 'building blocks' of social structure: 'Macro-social structures can be real, provided they are patterned aggregates that hold across micro-situations, or networks of repeated connections’ (Collins, 2004, p. 259; 1981; Barnes, 2000).

Such insights can be used to extend the analysis beyond the stages of entrepreneurial activity outlined above. Viewing entrepreneurial interaction ritual chains as a process of building shared trust suggests that the meshing of innovation rituals and market rituals is about the matching up of membership symbols and emotional energies, a matching that, once established, creates the trusting relationships within which commercial exchange relations have to be embedded. On the producers' side this attracts investment capital for expansion (as investors see that innovators are serious 
about making money); on consumers' side, the entry of known brands (e.g., IBM in the case of the PC market) instils the confidence and trust to buy the product. As trust builds, the entrepreneurs who led the way in establishing an innovation are, as Schumpeter noted, soon followed by competitors, who have to bear few of the costs or risks of innovation. Output increases, prices fall, and more consumers are able to enter the market. At this stage of initial expansion, participating in a new market/product (as producer or consumer) retains its sense of membership - its ritual characteristics - and, hence, its emotional energy charge. The increasing intensity of emotionally energised trust is expansive, spreading out to include more people and this, as Collins points out, 'is just what a business boom is' (p. 166). But as, by the same token, a business bust will be initiated by a loss of emotionally energised trust, the challenge for entrepreneurial companies is to continue to produce products that retain trust, membership commitment and emotional excitement - amongst, staff, investors and consumers - in the face of pressures towards the ritual dilution that accompanies expansion (Zhao, 2005). Although beyond the scope of the present paper, such an approach might provide interesting insights into the different forms of ‘mature entrepreneurship’ practiced by, say, the Microsoft and Apple corporations.

In terms of practice, our model proposes that an individual's ability to enact Schumpeterian entrepreneurialism will be related to their ability to gain emotional energy from situations where interaction rituals of innovation mesh with those of the market. As we have treated this only at an abstract level, it is worth considering what such 'meshing' might involve as a form of social interaction, thereby pointing towards some possible applications of this line of theorizing. 
Central to the meshing of different interaction rituals is the notion of overlapping memberships, generally established through membership symbols, e.g., interest in a specific activity or topic, possession of a shared terminology, respect for particular conventions of appearance or behaviour, enthusiasm for a particular emblem or idea. Thus, 'When several individuals value the same collective symbol, it is easy for them to evoke it in an interaction and achieve a high degree of focus around it. It provides a content to talk about or a focus for action' (Collins, 2004, p. 151). By the same token, where membership symbols fail to match up, interactions can often be tortuous and short-lived. The point to note is that if these membership symbols are to evoke motivating emotional energy and supportive group solidarity, they need to be part of concrete patterns of interaction, that is, they need to be used intersubjectively, not just understood subjectively (Rigg, 2005). The implication for practice is that innovative entrepreneurs need to grasp not only the symbols and discourses of the two (or possibly more) rituals they are trying to mesh, but also to be energised and excited by them (see also Segal et al, 2005). This is likely to mean actively participating in, rather than disinterestedly observing, an unfamiliar ritual, thereby tapping-in to its emotional energy and creating the potential to act as an 'EE-conduit' between this and more familiar rituals. Such interest can, of course be faked, but this is likely to involve the longer term risk of creating distrust, disillusionment or disinterest (as has been documented in situations involving 'emotional labour'; Hochschild, 1983). It is this active participation in each of the meshing rituals that is likely to create the opportunities to share, exchange and amalgamate ritual symbols and activities, creating solidarity and trust around a new hybrid ritual that can serve as a combined focus for EE. 
In some cases the hybrid rituals of Schumpeterian entrepreneurship may arise spontaneously, a fortuitous outcome of an individual's interaction history and experience. This does not mean, however, that many of the component skills could not, to some degree, be taught. For those inspired and motivated by business formation, there are two possible lessons. First, to consider framing opportunities not just in terms of a new and unexploited 'technology' (whether product or service), but also in relation to patterns of high intensity social interaction that are at an emergent stage and where business skills could be brought to bear. Second, to develop an interest in, and sensitivity to, patterns of social interaction, learning to identify those relationships that generate emotional energy and group solidarity, and to understand how symbols and discourses are deployed within groups. This can be used to facilitate effective membership of new and unfamiliar rituals and to explore the prospects for the deployment of business techniques in a way that is not going to destroy the relationships that give the 'opportunity' its dynamic potential. It is already established that social capital and social competence can influence entrepreneurial success (Baron and Markman, 2003). Our model suggests further reasons why training in social skills could benefit aspirant entrepreneurs, and also suggest some additional forms of social interaction that could be usefully addressed.

In conclusion, this paper has attempted to show that IRC theory can provide insights into aspects of Schumpeterian entrepreneurial conduct that have been largely overlooked by other theories. The absence of empirical data explicitly focused on this dimension of entrepreneurship means that this model must, at present, remain tentative. The illustrative data provided above provides only a superficial insight into the dynamics of interaction rituals and it could be objected that the account overstates 
their importance. We would maintain, however, that the theoretical relationship between ritualised interactions, group solidarity and individual emotional energy offers a sufficiently plausible explanation for the exceptional personal and collective dynamism necessary to initiate an innovative venture that it is worthy of further consideration and development.

\section{Notes}

\footnotetext{
1 The existence of relatively enduring feelings of pleasantness/unpleasantness is well supported in the literature, sometimes labelled mood (e.g., Forgas, 1992; Lazarus, 1991; Forgas and George, 2001; Kelly and Barsade, 2001; Watson and Tellegen, 1985). The construct is also similar to that of 'global emotions or feelings' that has been empirically validated in Lawler's related 'affect theory of social exchange' (Lawler 2001; Weiner 1985).
}

${ }^{2}$ As Collins (2004) points out, although programming is often presented as an isolated, 'nerdy' activity, programmers are, in practice, frequently participants in technophile networks through which solidarity and EE are generated.

${ }^{3}$ He was not alone in this; the opportunity presented by Intel's 8080 silicon chip - the basis of the Altair - was not spotted by the established computer powers (or Intel itself) who saw its enhanced processing power not as the basis for a personal computer, but as an integrated-systems component, powering, e.g., calculators or traffic lights.

${ }^{4}$ A similar case could be made regarding the emergence of Apple Computers and the role of Steve Jobs; see Cringely op cit, ch. 10.

\section{References}

Ashkanasy, N., Hartel, C. and Daus, C. (2002), "Diversity and Emotion: The New Frontiers in Organizational Behaviour Research”, Journal of Management, Vol. 28, pp. 307-338.

Baehr, P. (2005), “The sociology of almost everything”, Canadian Journal of Sociology Online, Jan.

http://www.arts.ualberta.ca/cjscopy/reviews/interactionritual.html

Barnes, B. (2000), Understanding Agency, Sage, London. 
Baron, R. (1998), “Cognitive mechanisms in entrepreneurship: when and why entrepreneurs think differently than other people”, Journal of Business Venturing, Vol. 13, pp. 275-294.

Baron, R. (2004), "Potential benefits of the cognitive perspective”, Journal of Business Venturing, Vol. 19, pp. 169-172.

Bower, T. (1988), Maxwell, Mandarin, London.

Bower, T. (1993), Tiny Roland, Heinemann, London.

Branson, R. (2000), Losing my Virginity, Virgin, London.

Burt, R. (2000), “The network entrepreneur”, in Swedberg, R. (ed) Entrepreneurship, Oxford University Press, Oxford, pp. 281-307.

Campbell-Kelly, M. (1995), "Development and structure of the international software industry, 1950-1990”, Business and Economic History, Vol. 24, pp. 73-110.

Collins, R. (1981), "On the Microfoundations of Macrosociology”, American Journal of Sociology, Vol. 86, pp. 984-1014.

Collins, R. (2004), Interaction Ritual Chains, Princeton University Press, Oxford.

Collins, R. (1990), "Stratification, emotional energy and transient emotions", in

Kempner, T. (ed.) Research Agendas in the Sociology of Emotions, State University of New York, Albany.

Cringely, R. (1996), Accidental Empires, Penguin, London.

Cringely, R. (2005a) Triumph of the Nerds, transcript 1, http://www.pbs.org/nerds/part1.html, accessed, 01.12.04 Cringely, R. (2005b) Triumph of the Nerds, transcript 2, http://www.pbs.org/nerds/part2.html, accessed, 01.12.04 Cringely, R. (2005c) Triumph of the Nerds, transcript 3, http://www.pbs.org/nerds/part3.html, accessed, 01.12.04

DiMaggio, P. (2002), "Endogenizing “Animal Spirits”: Towards a sociology of Collective response to Uncertainty and Risk”, in: Guillen, M., Collins, R., England, P. and Meyer, M. (eds.) The New Economic Sociology. Russell Sage, New York. Douglas, D. (2005), "The human complexities of entrepreneurial decision making: a grounded case considered”, International Journal of Entrepreneurial Behaviour and Research, Vol. 11, pp. 422-435.

Fineman, S. (2003), Understanding Emotion at Work, Sage, London.

Frieberger, P. and Swaine, M. (1984), Fire in the Valley: the Making of the Personal Computer, Berkeley, California.

Forgas, J. (1992), “Affect in Social Judgements and Decisions: A Multiprocess Model”, Advances in Experimental Social Psychology, Vol. 25, pp. 227-275.

Forgas, J. and George, J. (2001), “Affective Influences on Judgements and Behaviour in Organizations: An Information Processing Perspective”, Organizational Behaviour and Human Decision Processes, Vol. 86, pp. 3-34.

Gabriel, Y. and Griffiths, D. (2002), "Emotion, Learning and Organizing”, The Learning Organization, Vol. 9, pp. 214-221.

Gandal, N., Greenstein, S. and Salant, D. (1999), “Adoptions and orphans in the early microcomputing market”, Journal of Industrial Economics, Vol. XLVII, pp. 87-105. Goss, D. (2005a), "Schumpter's legacy? Interaction and emotions in the sociology of entrepreneurship”, Entrepreneurship: Theory and Practice, Vol. 29, pp. 205-218. Goss, D (2005b), "Entrepreneurship and the 'social': towards a deference-emotion theory”, Human Relations, Vol. 58:5, pp. 617-636

Granovetter, M. (1985), "Economic Action and Social Structure: The Problem of Embeddedness”, American Journal of Sociology, Vol. 91, pp. 481-510. 
Greve, A. and Salaff, J. (2003), "Social networks and entrepreneurship", Entrepreneurship Theory and Practice, Vol. 27, pp. 1-22.

Hochschild, A. (1983), The Managed Heart, University of California Press, Berkely. Jack, S. and Anderson, A. (2002), "The Effects of Embeddedness on Entrepreneurial Process”, Journal of Business Venturing, Vol. 17, pp. 467-487.

Kelly, J. and Barsade, S. (2001), "Mood and Emotions in Small Groups and Work Teams”, Organizational Behaviour and Human Decision Processes, Vol. 86, pp. 99130.

Kets de Vries, M. (1996), “The anatomy of the entrepreneur”, Human Relations, Vol. 49, pp. 853-884.

Kirzner, I. (1973), Competition and Entrepreneurship, , University of Chicago Press, Chicago.

Langlois, R. (1994), “Cognition and capabilities: opportunities seized and missed in the history of the computer industry", http://econwpa.wustl.edu:8089/eps/io/papers/9406/9406003.pdf

Lawler, E. (2001), “An affect theory of social exchange”, American Journal of Sociology, Vol. 107, pp. 321-352

Letiche, H. and Hagemeijer, R. (2004), “Linkages and Entrainment”, Journal of Organizational Change Management, Vol.17, pp. 365-382.

Lowe, J. (1998), Bill Gates Speaks, Wiley, New York.

Lupton, D. (1998), The Emotional Self, Sage, London.

Markman, G. and Baron, R. (2003), "Person-entrepreneurship fit: why some people are more successful as entrepreneurs than others", Human Resource Management Review, Vol. 13, pp. 281-301.

Mitchell, R., Busenitz, L., Lant, T., McDougall, P., Morse, E. and Smith, J. (2002), "Toward a theory of entrepreneurial cognition", Entrepreneurship Theory and Practice, Vol. 26, pp. 93-104

Mitchell, R., Busenitz, L., Lant, T., McDougall, P., Morse, E. and Smith, J. (2004), "The distinctive and inclusive domain of entrepreneurial cognition research", Entrepreneurship Theory and Practice, Vol. 28, pp. 505-518 Naughton, J. (2000), A brief history of the future, Phoenix, London.

Neergaard, H., Shaw, E. and Carter, S. (2005), “The impact of gender, social capital and networks on business ownership: a research agenda”, International Journal of Entrepreneurial Behaviour and Research, Vol. 11, pp. 338-357.

Rigg, C. (2005), "It's the way they talk: a discourse analysis of managing in two small businesses”, International Journal of Entrepreneurial Behaviour and Research, Vol. 11, pp. 58-75.

Roddick, A. (2000), Business as Unusual, Thorsons, London.

Schumpeter, J. (1934), The Theory of Economic Development, Harvard University Press, Cambridge.

Schwartz, R., Teach, R. and Birch, N. (2005), “A longitudinal study of entrepreneurial firms opportunity recognition and product development management strategies”, International Journal of Entrepreneurial Behaviour and Research, Vol. 11, pp. 315329.

Segal, G., Borgia, D. and Schoenfeld, J. (2005), “The motivation to become an entrepreneur”, International Journal of Entrepreneurial Behaviour and Research, Vol. 11, pp. 42-57.

Shane, S. (2003), A General Theory of Entrepreneurship, Edward Elgar, Cheltenham. 
Smardon, R. (2005), "Where the action is: the microsociological turn in educational research”, Education Researcher, January, pp. 20-25

Smith, R. (2004), "Rural rogues: a case story on the 'smokies' trade”, International Journal of Entrepreneurial Behaviour and Research, Vol. 10, pp. 277-294.

Steinmueller, W. E. (1995), “The US software industry”, paper prepared for ICSIP, Berkeley, Cal. http://www.merit.unimaas.nl/publications/rmpdf/1995/rm1995-009.pdf Watson, D. and Tallen, A. (1985), "Towards a Consensual Structure of Mood”, Psychological Bulletin, Vol. 98, pp. 219-235.

Weiner, B. (1986), "An Attributional Theory of Achievement Motivation and Emotion”, Psychological Review, Vol. 92, pp. 548-73.

Yli-Renko, H., Autio, E. and Sapienza, J. (2001), Social capital, knowledge acquisition and knowledge exploitation in young technology-based firms”, Strategic Management Journal, Vol. 22, pp. 587-613

Zafirovski, M. (1999), "Probing into the social layers of entrepreneurship: outlines of the sociology of enterprise”, Entrepreneurship and Regional Studies, Vol. 11, pp. 351-371.

Zhao, F. (2005), "Exploring the synergy between entrepreneurship and innovation”, International Journal of Entrepreneurial Behaviour and Research, Vol. 11, pp. 25-41. 